\title{
Quantification of bioactive compounds in guava at different ripening stages
}

\author{
Shukla, S., Kushwaha, R., Singh, M., Saroj, R., Puranik, V., Agarwal, R. and *Kaur, D. \\ Centre of Food Technology, University of Allahabad, Prayagraj, 211002, India
}

\begin{abstract}
Article history:
Received: 28 September 2020

Received in revised form: 25

November 2020

Accepted: 2 February 2021

Available Online: 16 May

2021
\end{abstract}

Keywords:

Guava cultivars,

Bioactive compounds,

HPLC,

Principal Component

Analysis

DOI:

https://doi.org/10.26656/fr.2017.5(3).554

\begin{abstract}
Guava (Psidium guajava L.) is one of the most important tropical fruits belonging to the genus Psidium and the Myrtaceae family and claim to have phenolic compounds that have been reported to possess strong antioxidant activity. This study was aimed to evaluate the bioactive constituents in guava cultivars at different ripening stages by HPLC. The five guava cultivars were selected at different ripening stages and the bioactive components were analysed by high-pressure liquid chromatography. The quantification of bioactive compounds revealed that the highest amount of bioactive compounds was found in cultivar Safeda at the unripe stage, while a minimum amount was found in ripe Apple Colour guava cultivar. The six bioactive compounds were quantified in the range of gallic acid $(9.46-63.08 \mathrm{mg} / 100 \mathrm{~g})$, quercetin $(0.11-2.51$ $\mathrm{mg} / 100 \mathrm{~g})$, myrcetin $(0.09-0.034 \mathrm{mg} / 100 \mathrm{~g})$, ascorbic acid $(7.45-75.07 \mathrm{mg} / 100 \mathrm{~g})$, apegenin $(0.01-0.032 \mathrm{mg} / 100 \mathrm{~g})$ and lycopene $(0.34-0.92 \mathrm{mg} / 100 \mathrm{~g})$. The exploratory evaluation of guava samples was performed through Principal Component Analysis (PCA), the bioactive compounds, lycopene, myricetin, and quercetin are dominant variables on this $\mathrm{PC} 1(61.52 \%)$ (Scores better than 0.7$)$, thereby causing greater variability among these samples. The second principal component (PC2) represents $16.54 \%$ of the total variance and the ascorbic acid, gallic acid and apeginin (score better than 0.7 ), are the dominant variables on this PC.
\end{abstract}

\section{Introduction}

It is known that plants are a rich source of secondary metabolites like flavonoids, carotenoids, alkaloids, terpenoids and tannins and they have been implicated in several therapeutic methodologies. Psidium guajava L. is a small tree native to Central America; it is popularly known as guava and belongs to the myrtle family (Myrtaceae). The guava tree has been distributed through many countries as a result of its capacity to grow in tropical and subtropical conditions (Morton, 1987). Compounds such as carotenoids and flavonoids have already been recognised as either inhibitor of oxidative stress or compounds that reduce oxidative stress (Sies and Stahl, 1995) because they can act with antioxidants that are able to inactivate free radicals and their action (Halliwell, 1996; Devasagayam et al., 2004). The flavonoids, known as a natural antioxidant, are the main bioactive compounds found in fruits (Robbins, 2003; Lampila et al., 2009). Carotenoids are abundant in fruits and vegetables but are usually masked by green-coloured chlorophyll. The degradation of chlorophyll during maturation enables the carotenoids to be visualized, for example, in dying leaves during autumn and matured fruits (tomatoes, oranges, grapefruit) (Rabinowitch et al., 1982). The key nutritional role of carotenoids is provitamin A, which is commonly known to improve vision. Additionally, carotenoids are known to act as an antioxidant in the human body (Perera and Yen, 2007; Rao and Ali, 2007). High-performance liquid chromatography (HPLC) is currently the preferred procedure for carotenoid and flavonoid analysis. HPLC columns offer high resolving power and numerous papers have been published on the HPLC separation of carotenoids (Rodriguez-Amaya, 2015). Only a few of these papers included quantification, however, and discrepancies continue to exist in the reported quantitative data.

The nutritional and health-promoting properties of guava, together with the increased interest in its antioxidant properties, indicate the potential nutraceutical use of this fruit (Ho et al., 2012). Therefore, there is a need for the proper selection of cultivars with the appropriate bioactive composition for the intended use of the fruit. This study focuses on the 
isolation of different bioactive compounds from five guava cultivars fruit extract at different ripening stages.

\section{Materials and methods}

\subsection{Plant materials}

A total of five guava cultivars namely, Lalit, Allahabad Surkha, Allahabad Safeda, Chittidar and Apple colour were collected at different ripening stages from an orchard in Khusroobagh (under the Department of Horticulture and Food Processing, Uttar Pradesh Government), Allahabad and stored at $15 \pm 2^{\circ} \mathrm{C}$ with a relative humidity of $90-95 \%$.

\subsection{Sample preparation}

Guava was weighed at $1 \mathrm{~g}$ (triplicate, $\mathrm{n}=3$ ) and extracted $(1: 50, \mathrm{w} / \mathrm{v})$ in $10 \%$ dimethylsulphoxide in $90 \%$ methanol $(3 \times 50 \mathrm{~mL}, 4 \mathrm{hr}$ each $)$ and the supernatants were obtained by centrifugation at $5000 \mathrm{rpm}$ for $20 \mathrm{mins}$. Phenolic acids were separated by ethyl acetate phase separation $(4 \times 50 \mathrm{~mL})$ and the fractions were pooled (Subba Rao and Murlikrishna, 2002).

\subsection{Estimation of Polyphenols and antioxidant analysis}

Fruit extract of guava cultivars along with standard solutions was prepared and filtered through a $0.22 \mu \mathrm{m}$ filter (Milli-pore, Billerica, USA). Samples were analysed on analytical HPLC (Metrohm Technologies) fitted with an automatic degasser, C-18 column $4.6 \times 250$ $\mathrm{mm}$ and a Photo-diode array detector (DAD). A mobile phase of different organic solvents acidified methanol: water (50:50), petroleum ether: water (10:90), ethanol: water $(10: 90)$ and acetonitrile: water $(10: 90 \mathrm{v} / \mathrm{v})$ was degassed and filtered through a $0.22 \mu \mathrm{m}$ filter paper. The detector was set in scan mode, 210-550 $\mathrm{nm}$ during the analysis, while the flow rate was set at $1 \mathrm{~mL} / \mathrm{min}$. A sample volume of $20 \mu \mathrm{L}$ was injected into the column. The polyphenolic and antioxidant content of extract were measured by comparing peak retention time and area under the chromatographic peak of standard solution.

\subsection{Statistical analysis}

All the experiments were performed in triplicates and mean were reported. Multivariate technique Principal Component Analysis (PCA) was applied for a better understanding of the characteristics results obtained by different analyses.

\section{Results and discussion}

\subsection{Isolation of antioxidants from guava cultivars}

In the present study, bioactive compounds of guava fruit at different ripening stages have been investigated by different extraction procedures. The comparative efficiency of the solvents was estimated from the total peak areas of the HPLC chromatograms obtained. The maximum extraction of the bioactive compound was observed in acetonitrile: water $(10: 90 \mathrm{v} / \mathrm{v})$, which was proved to be a most efficient combination for polyphenol (gallic acid), three flavonoids (myrcetin, apigenin and quercetin), ascorbic acid and carotenoid (lycopene) present in all the samples.

\subsection{Quantification of phenolic acid}

Phenolic compounds in fruits have received significant attention in recent years due to their potent antioxidant capacities and their ability to reduce the risk of diseases caused by oxidative stress, such as cancer (Kubola and Siriamornpun, 2011; Deng et al., 2013; de Carvalho-Silva et al., 2014; Siriamornpun et al., 2015). In the present study, gallic acid was identified and quantified in the green and ripe guava fruits. The results showed that the content and composition of gallic acid was significantly different $(p<0.05)$ between the cultivars and the maturity of the fruits. The gallic acid clearly decreased with ripening stages in all the selected guava cultivars.

The unripe stage of Lalit guava had the major amount of gallic acid $(63.08 \mathrm{mg} / 100 \mathrm{~g})$ among all the cultivars. The least amount of Gallic acid was seen in the ripe Lalit guava $(9.46 \mathrm{mg} / 100 \mathrm{~g})$. The semi-ripe variety, however, had a moderate level of gallic acid (25.09 $\mathrm{mg} / 100 \mathrm{~g}$ ). The level of Gallic acid was therefore found to be more in the unripe stage as compared to the other two stages in the cultivars. The semi-ripe and ripe stages of Surkha and Safeda had a gallic acid level of 31.73 $\mathrm{mg} / 100 \mathrm{~g} ; 11.30 \mathrm{mg} / 100 \mathrm{~g}$; and $24.18 \mathrm{mg} / 100 \mathrm{~g}$, respectively. The gallic acid of semi-ripe and ripe varieties of Chittidar cultivar was $22.18 \mathrm{mg} / 100$ and $10.09 \mathrm{mg} / 100 \mathrm{~g}$, respectively. The Gallic acid content of unripe Chittidar guava samples had nearly double that of the semi-ripe Safeda cultivar (i.e., $49.08 \mathrm{mg} / 100 \mathrm{~g}$ ). The unripe stage of Apple colour had the second-highest amount of gallic acid among the five cultivars (60.11 $\mathrm{mg} / 100 \mathrm{~g})$. The semi-ripe and ripe variety showed a gallic acid level of $28.87 \mathrm{mg} / 100 \mathrm{~g}$ and $12.54 \mathrm{mg} / 100 \mathrm{~g}$, respectively. The amount of gallic acid in the unripe fruit of all fruits investigated was higher than that of the ripe fruit. Similar results were reported by Siriamornpun and Kaewseejan (2017). The maximum decrease in gallic acid content $(85.03 \%)$ was found in cultivar Lalit, while Apple colour showed a decrease of $79.14 \%$ during the ripening of fruits.

Kondo et al. (2005) also detected gallic acid, catechin, epicatechin and chlorogenic acid in guava, out 
of all these compounds catechin found in the highest concentration $(45 \mu \mathrm{mol} / \mathrm{kg}$ of fresh weight). However, Freda et al. (2017) found $90.90 \mathrm{mg} / 100 \mathrm{~g}$ of gallic acid was present in red guava pulp, $79.80 \mathrm{mg} / 100 \mathrm{~g}$ in conventional sweet guava paste and $82.60 \mathrm{mg} / 100 \mathrm{~g}$ gallic acid in light sweet guava paste.

\subsection{Quantification of flavonoids}

Flavonoids are one of the most important polyphenolic compounds with human health benefits due to their potent antioxidant and pharmacological effects (Miean and Mohamed, 2001; Khanam et al., 2012). In our study, three flavonoids, namely myrcetin, apigenin and quercetin were identified and quantified in the unripe semi-ripe and ripe fruits from the five fruits. According to Siriamornpun and Kaewseejan (2017), flavonoids were significantly different depending on cultivar and ripeness of the fruit. The differences in the amount of flavonoids may be due to the genetic variability and the ripening leading to variations in the biosynthesis of flavonoids in these fruits.

The highest myrcetin was found in the ripe Surkha $(0.34 \mathrm{mg} / 100 \mathrm{~g})$ and the lowest count was found in the unripe stage of the same variety $(0.011 \mathrm{mg} / 100 \mathrm{~g})$. Similar patterns were seen with cultivar Apple colour; $(0.028 \mathrm{mg} / 100 \mathrm{~g} ; 0.015 \mathrm{mg} / 100 \mathrm{~g}$ and $0.11 \mathrm{mg} / 100 \mathrm{~g})$, respectively in unripe, semi-ripe and ripe stages of maturity. While other cultivars showed an opposite pattern as the content of myrcetin increases with maturity (Figure 1). The unripe, semi-ripe and ripe stages of Lalit cultivar had increased Myrcetin levels with maturity viz. $(0.025 \mathrm{mg} / 100 \mathrm{~g}),(0.034 \mathrm{mg} / 100 \mathrm{~g})$ and $(0.042 \mathrm{mg} / 100$ g); Chittidar $(0.031 \mathrm{mg} / 100 \mathrm{~g} ; 0.016 \mathrm{mg} / 100 \mathrm{~g}$; and 0.09 $\mathrm{mg} / 100 \mathrm{~g}$ ), respectively. A similar pattern has been observed in Safeda cultivar (Table 1). The maximum increase in myrcetin acid content $(292.86 \%)$ was found in cultivar Apple colour, while Lalit showed an increase of $68.00 \%$ during the ripening of fruits. Musa et al. (2015) suggested the levels of myricetin in Sungkai guava fruit, flesh, and skin were 80.38, 93.75, and 51.60 $\mathrm{mg} / \mathrm{kg}$, respectively, and for Semenyih guava, the levels were $83.05,84.00$, and $73.75 \mathrm{mg} / \mathrm{kg}$ for fruit, flesh, and skin, respectively.

The flavonoid that was found to be in the least amount was apigenin, besides being absent in the unripe stage of all the selected cultivars. Among the cultivars where Apigenin was found, the semi-ripe variety of Lalit Guava had the least amount $(0.01 \mathrm{mg} / 100 \mathrm{~g})$ of flavonoid as compared to the ripe variety $(0.025 \mathrm{mg} / 100 \mathrm{~g})$. The apiginine content in semi-ripe stage and ripe stage of Surkha was $0.015 \mathrm{mg} / 100 \mathrm{~g}$ and $0.029 \mathrm{mg} / 100 \mathrm{~g}$, respectively. The semi-ripe and ripe stages of Safeda and Chittidar had apigenin levels of $0.009 \mathrm{mg} / 100 \mathrm{~g}, 0.015$ $\mathrm{mg} / 100 \mathrm{~g}, 0.022 \mathrm{mg} / 100 \mathrm{~g}$ and $0.012 \mathrm{mg} / 100 \mathrm{~g}$, respectively. Apigenin was also absent in the semi-ripe stage of Apple colour but was found in the ripe stage $(0.023 \mathrm{mg} / 100 \mathrm{~g})$. Apegenin was not detected in all fractions from both sungkai and semenyih guava (pink guava) as suggested by Musa et al. (2015), which is in agreement with the present work. While Miean and Mohamed (2001) reported guava contains 550 and 579 $\mathrm{mg} / \mathrm{kg}$ of the dry weight of the flavonols myricetin and apigenin, respectively. The maximum increase in apigenin content $(275.00 \%)$ was found in cultivar Safeda, while Lalit showed an increase of $93.33 \%$ during the ripening of fruits, but cultivar Chittidar showed a $45.45 \%$ decrease in apigenin content during the ripening from semi-ripe to ripe.

Table 1. Bioactive compounds of guava cultivars at different ripening stages

\begin{tabular}{|c|c|c|c|c|c|c|c|}
\hline \multicolumn{2}{|c|}{ Cultivars } & \multicolumn{6}{|c|}{ Compounds } \\
\hline \multicolumn{2}{|c|}{ Ripening stages } & $\begin{array}{l}\text { Gallic acid } \\
(\mathrm{mg} / 100 \mathrm{~g})\end{array}$ & $\begin{array}{l}\text { Myrcetin } \\
(\mathrm{mg} / 100 \mathrm{~g})\end{array}$ & $\begin{array}{l}\text { Apegenin } \\
(\mathrm{mg} / 100 \mathrm{~g})\end{array}$ & $\begin{array}{l}\text { Quercetin } \\
(\mathrm{mg} / 100 \mathrm{~g})\end{array}$ & $\begin{array}{c}\text { Ascorbic acid } \\
(\mathrm{mg} / 100 \mathrm{~g})\end{array}$ & $\begin{array}{l}\text { Lycopene } \\
(\mu \mathrm{g} / \mathrm{g})\end{array}$ \\
\hline \multirow{3}{*}{ Lalit } & Unripe & $63.08 \pm 0.025$ & $0.025 \pm 0.003$ & - & $2.43 \pm 0.01$ & $9.11 \pm 0.30$ & - \\
\hline & Semiripe & $25.09 \pm 0.03$ & $0.034 \pm 0.001$ & $0.01 \pm 0.001$ & $1.02 \pm 0.02$ & $19.09 \pm 0.13$ & - \\
\hline & Ripe & $9.46 \pm 0.02$ & $0.042 \pm 0.002$ & $0.025 \pm 0.004$ & $0.98 \pm 0.03$ & $35.00 \pm 0.21$ & $9.00 \pm 1.7$ \\
\hline \multirow{3}{*}{ Surkha } & Unripe & $58.8 \pm 0.023$ & $0.11 \pm 0.07$ & - & $2.51 \pm 0.03$ & $11.28 \pm 0.14$ & - \\
\hline & Semiripe & $31.73 \pm 0.090$ & $0.23 \pm 0.067$ & $0.015 \pm .007$ & $0.34 \pm 0.01$ & $28.11 \pm 0.12$ & - \\
\hline & Ripe & $11.30 \pm 0.035$ & $0.34 \pm 0.054$ & $0.029 \pm 0.003$ & $0.11 \pm 0.03$ & $49.34 \pm 0.23$ & $8.6 \pm 1.03$ \\
\hline \multirow{3}{*}{ Safeda } & Unripe & $59.11 \pm 0.055$ & $0.016 \pm 0.001$ & $0.004 \pm 0.001$ & $3.22 \pm 0.05$ & $48.09 \pm 0.13$ & - \\
\hline & Semiripe & $24.18 \pm 0.053$ & $0.027 \pm 0.01$ & $0.009 \pm 0.0015$ & $1.02 \pm 0.04$ & $56.10 \pm 0.17$ & - \\
\hline & Ripe & $11.78 \pm 0.055$ & $0.037 \pm 0.034$ & $0.015 \pm 0.003$ & $0.89 \pm 0.03$ & $75.07 \pm 0.26$ & - \\
\hline \multirow{3}{*}{ Chittidar } & Unripe & $49.08 \pm 0.06$ & $0.031 \pm 0.00$ & - & $1.23 \pm 0.02$ & $10.22 \pm 0.46$ & - \\
\hline & Semiripe & $22.18 \pm 0.03$ & $0.016 \pm 0.03$ & $0.022 \pm 0.04$ & $0.93 \pm 0.07$ & $22.45 \pm 0.35$ & - \\
\hline & Ripe & $10.09 \pm 0.06$ & $0.09 \pm 0.002$ & $0.012 \pm 0.01$ & $0.56 \pm 0.02$ & $38.90 \pm 0.23$ & $3.7 \pm 0.09$ \\
\hline \multirow{3}{*}{$\begin{array}{l}\text { Apple } \\
\text { colour }\end{array}$} & Unripe & $60.11 \pm 0.07$ & $0.028 \pm 0.001$ & - & $2.54 \pm 0.01$ & $7.45 \pm 0.22$ & - \\
\hline & Semiripe & $28.87 \pm 0.06$ & $0.015 \pm 0.03$ & - & $1.72 \pm 0.08$ & $18.90 \pm 0.11$ & $9.4 \pm 2.01$ \\
\hline & Ripe & $12.54 \pm 0.06$ & $0.11 \pm 0.01$ & $0.023 \pm 0.01$ & $0.44 \pm 0.02$ & $26.04 \pm 0.33$ & $33.2 \pm 4.13$ \\
\hline
\end{tabular}




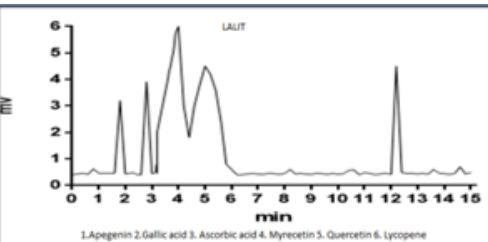

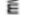
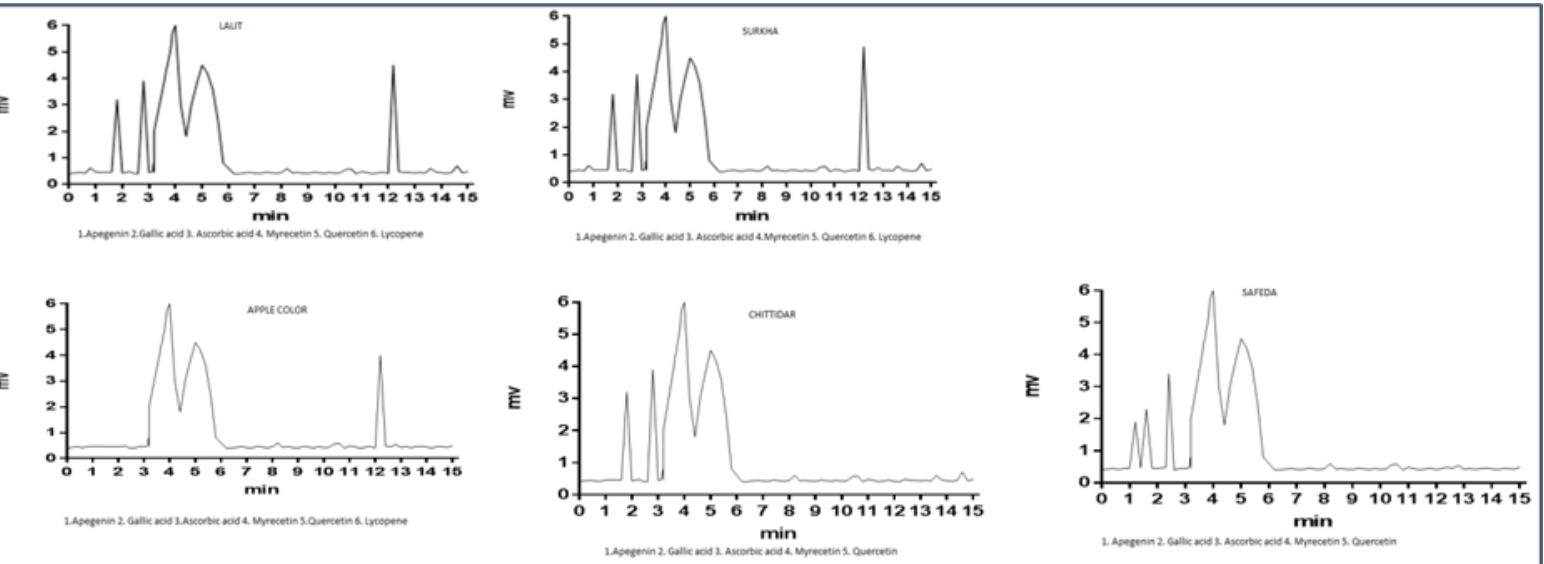

Figure 1. HPLC chromatogram of fully ripened guava cultivars Lalit, Surkha, Apple Colour, Chittidar and Safeda using C-18 column eluted with methanol: acetonitrile as mobile phase.

The quercetin was the major flavonoid present in the fruit, and the highest amount was found in Unripe Safeda $(3.22 \mathrm{mg} / 100 \mathrm{~g})$ and the lowest in the ripe stage of Surkha $(0.11 \mathrm{mg} / 100 \mathrm{~g})$. The level of Quercetin was decreased with maturity in all three stages. The unripe, semi-ripe and ripe stages of Lalit guava had the level of $2.43 \mathrm{mg} / 100 \mathrm{~g}, 1.02 \mathrm{mg} / 100 \mathrm{~g}$ and $0.98 \mathrm{mg} / 100 \mathrm{~g}$ of flavonoid, respectively (Table 1). Surkha cultivar showed levels of $2.51 \mathrm{mg} / 100 \mathrm{~g}$ and $0.34 \mathrm{mg} / 100 \mathrm{~g}$ of flavonoid in unripe and semi-ripe stages, respectively and a similar trend was followed by Safeda and Chittidar cultivars. Apple colour also showed decreased quercetin level along with the stages of maturity viz. $2.54 \mathrm{mg} / 100 \mathrm{~g}$ in unripe, $1.72 \mathrm{mg} / 100 \mathrm{~g}$ in semi-ripe and $0.44 \mathrm{mg} / 100 \mathrm{~g}$ in the ripe stage. The maximum decrease in quercetin content $(95.62 \%)$ was found in cultivar Surkha, while Chittidar showed a decrease of $54.47 \%$ during the ripening of fruits. The concentration of phenolic bioactive compounds in fruits depends on the degree of maturity, variety, climate, soil composition, geographic location, and storage conditions, and other factors, which explains the discrepancy between data from different articles, for the same type of sample (Das Santos et al., 2017). In the previous study on fresh and processed Brazilian fruits by Hoffmann - Ribani et al. (2009), the concentration of quercetin in guava $(1.30 \mathrm{mg} / 100 \mathrm{~g})$ is compatible with the values found in this study. In the current study maximum quercetin was found in unripe Safeda cultivar which is similar to results reported by Das Santos et al. (2017), that is high quercetin content was found in white and green guava cultivars as compared to others.

\subsection{Quantification of ascorbic acid}

In addition to being the biologically active form of vitamin $\mathrm{C}$, is the most commonly found and widely distributed in products of plant origin. It is primarily in citrus fruits and leafy vegetables. They are characterized as poor sources of vitamin $\mathrm{C}$. The vitamin content of the fruit can vary, depending on the species, maturity stage, genetic variants, postharvest handling, storage conditions, and processing. The content and stability of these nutrients in fresh food can influence its nutritional quality (Szeto et al., 2002). The highest amount of ascorbic acid was found in the ripe Safeda guavas (75.07 $\mathrm{mg} / 100 \mathrm{~g}$ ) and the lowest in the unripe stage of Apple colour guava $(7.45 \mathrm{mg} / 100 \mathrm{~g})$. The Lalit guava showed a moderate amount of ascorbic acid with the least in the unripe stage $(9.11 \mathrm{mg} / 100 \mathrm{~g})$. The ascorbic acid levels in Surkha were $11.28 \mathrm{mg} / 100 \mathrm{~g}, 28.11 \mathrm{mg} / 100 \mathrm{~g}$ and 49.34 $\mathrm{mg} / 100 \mathrm{~g}$ respectively in the unripe, semi-ripe and ripe stages. Chittidar showed the level of ascorbic acid in unripe, semi-ripe and ripe stages were $10.22 \mathrm{mg} / 100 \mathrm{~g}$, $22.45 \mathrm{mg} / 100 \mathrm{~g}$ and $38.90 \mathrm{mg} / 100 \mathrm{~g}$, respectively. Levels of ascorbic acid seen in the Apple colour cultivar were $18.90 \mathrm{mg} / 100 \mathrm{~g}$ and $26.04 \mathrm{mg} / 100 \mathrm{~g}$ in the semiripe and ripe stages respectively (Table 1). Hence, a considerable increment of the ascorbic acid level was seen in all the five cultivars with maturity, from unripe, semi-ripe, till the ripe stages of each cultivar. The maximum decrease in quercetin content $(337.41 \%)$ was found in cultivar Surkha, while Chittidar showed a decrease of $56.10 \%$ during the ripening of fruits.

Mitra et al. (1983) reported that Vitamin C content was highest in Lucknow-49 and Apple Colour, whereas Pear Shaped, Red Fleshed and Harijha varieties had poor Vitamin C content. According to Singh et al. (1984), Guava varieties Anakapalli, Kothrud, Lucknow-49, Portugal and Seedless contained high ascorbic acid content $(201.20 \mathrm{mg} / 100 \mathrm{~g}$ to $225.70 \mathrm{mg} / 100 \mathrm{~g})$, while cultivars. Chittidar $(84.00 \mathrm{mg} / 100 \mathrm{~g})$ had a minimum amount of ascorbic acid. Chauhan et al. (1986) observed that ascorbic acid content showed considerable fluctuation during different seasons and it was highest in cultivar Allahabad Safeda (329.28 mg/100 g) during the rainy season. Thuaytong and Anprung (2011) also reported the ascorbic acid content in white and red guava fruit up to 130.00 and $112.00 \mathrm{mg} / 100 \mathrm{~g}$, respectively which is higher than the present study. 


\subsection{Quantification of lycopene}

Lycopene could only be detected in the ripened stage of the cultivar (with the highest amount in the apple colour cultivar i.e., $0.92 \mathrm{mg} / 100 \mathrm{~g}$ ); except being present in the semi-ripe stage of Apple colour variety (lowest, $0.34 \mathrm{mg} / 100 \mathrm{~g}$ ). It was absent throughout the ripening in cultivar Safeda (Table 1). Moreover, a considerable amount of Lycopene was seen in the ripe stages of two cultivars Lalit $(0.90 \mathrm{mg} / 100 \mathrm{~g})$ and Surkha $(0.86 \mathrm{mg} / 100$ g). Lycopene extraction from Psidium guajava L. carried out by Fabienne Priam et al. (2017) suggested that the lycopene concentration obtained was $2.11 \mathrm{mg} / 100 \mathrm{~g}$ in guava which is higher than the findings of the current study. Rani et al. (2017) also reported a higher amount of lycopene in red guava fruit i.e., $52.16 \mathrm{mg} / \mathrm{kg}$. The pink/ red flesh colour found in some varieties of guava has been attributed to the presence of lycopene. Poher et al. (2003) reported lycopene content as 4.5 to $5.5 \mathrm{mg} / 100 \mathrm{~g}$ in Red fleshed guava variety. Ordóñez-Santos and Vázquez-Riascos (2010) carried out a study on pink guava fruit and found the lycopene content of the fresh fruit to be $3.55 \mathrm{mg} / 100 \mathrm{~g}$. However, Boora (2012) observed a higher amount $(7.45 \mathrm{mg} / 100 \mathrm{~g})$ of lycopene content in fresh Punjab Pink variety of guava. Kumar (2015) found that the lycopene content of fresh fruits of Punjab Pink was 3.74 mg/100 g. Wilberg and RodriguezAmaya (1995) reported lycopene content of about 5.34 $\mathrm{mg} / 100 \mathrm{~g}$ in guava fruit which is similar to the present study.

Based on current findings, it has been demonstrated that unripe fruits of all cultivars studied could serve as potential sources of bioactive compounds, especially phenolics and flavonoids. Thus, this information may be useful for consumers who need to choose fruits that provide the highest specific bioactive compounds and health benefits. Moreover, it is considered that the profile of bioactive compounds could be a potential metabolite marker to determine the ripening stages of the three fruits studied as the fruit undergoes the ripening the ascorbic acid content decreases while the amount of lycopene increases (Table 1).

\subsection{Principal component analysis (PCA)}

An exploratory evaluation involving five guava cultivars was performed using Principal Component Analysis (PCA), comprising six variables: gallic acid, quercetin, apigenin, myricetin, ascorbic acid, and lycopene $(\mathrm{mg} / 100 \mathrm{~g})$ by HPLC. PCA analysis was applied, after auto-scaled, using the Software IBM SPSS Statistics 20. Components $(\mathrm{PC} 1 \times \mathrm{PC} 2)$ describe $78.06 \%$ of the total variance of the data and provide discriminatory information related to the samples. Figure 2 shows the score plots $(\mathrm{PC} 1 \times \mathrm{PC} 2)$ of the principal

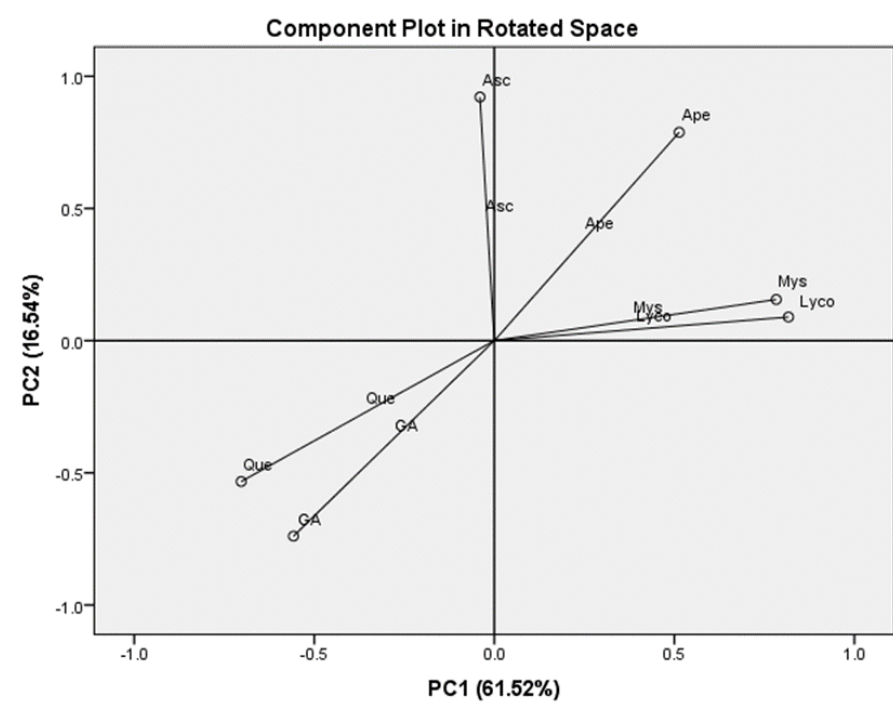

Figure 2. Principal component analyses for 5 guava cultivars (Psidium gujava sp.) and the eigenvector circle of the variable: myrcetin (Mys), Querecetin (Que), apeginin (Ape), Lycopene (Lyco) and ascorbic acid (Asc)

component analysis (PCA) at different ripening stages of guava (Psidium guajava L.) in relation to bioactive components $(\mathrm{mg} / 100 \mathrm{~g})$ by HPLC. The eingen values of the correlation matrix for PC1, and PC2, were, respectively: 3.69 and 0.99 . The first principal component (PC1) describes $61.52 \%$ of the total variance. The bioactive compounds: lycopene, myricetin, and quercetin are the dominant variables on this PC (scores better than 0.7), thereby causing greater variability among these samples. The second principal component (PC2) represents $16.54 \%$ of the total variance and the ascorbic acid, gallic acid and apeginin (score better than 0.7 ), are the dominant variables on this PC. Similarly, Dantas et al. (2013), Dos Santos et al. (2017), had classified the guava fruits according to their maturity stages by conducting PCA analysis.

\section{Conclusion}

This study was performed to determine the levels of gallic acid, ascorbic acid, quercetin, apigenin, myricetin and lycopene between ripening stages and cultivars. The results indicate that guava is a rich source of polyphenols, ascorbic acid and flavonoids and lycopene and also affected by the type of cultivar and their maturity stages. The lycopene content was found absent in cultivar Safeda and present only at the ripe stage in other cultivars except for cultivar Apple colour. Overall, the cultivar with the least amount of total bioactive compounds was the Apple colour (ripe) and with the highest amount of bioactive compounds was the Safeda (unripe stage), which shows cultivar and ripening both affect the quality of fruits. Therefore, present results showed that guava constitutes higher antioxidant activity and extraction of these bioactive components can be 
utilized as a functional food.

\section{Conflict of interest}

The authors declare no conflict of interest.

\section{Acknowledgments}

The authors are highly thankful to the Centre of Food Technology University of Allahabad, for providing facilities to carry out the investigation.

\section{References}

Boora, R.S. (2012). Improvement in guava (Psidium guajava L.)-A review. Agricultural Reviews, 33(4), 341-349.

Chauhan, R., Kapoor, A.C. and Gupta, O.P. (1986). Note on the effect of cultivar and season on the chemical composition of guava fruits. Haryana Journal of Horticultural Sciences, 15(3-4), 228-230.

de Carvalho-Silva, L.B., Dionísio, A.P., da Silva Pereira, A.C., Wurlitzer, NJ., de Brito, E.S., Bataglion, G.A., Brasil, I.M., Eberlin, M.N. and Liu, R.H. (2014). Antiproliferative, antimutagenic and antioxidant activities of a Brazilian tropical fruit juice. LWTFood Science and Technology, 59(2), 1319-1324. https://doi.org/10.1016/j.lwt.2014.04.002

Deng, G.F., Xu, X.R., Zhang, Y., Li, D., Gan, R.Y. and Li, H.B. (2013). Phenolic compounds and bioactivities of pigmented rice. Critical Reviews in Food Science and Nutrition, 53(3), 296-306. https:// doi.org/10.1080/10408398.2010.529624

Devasagayam, T.P.A., Tilak, J.C., Boloor, K.K., Sane, K.S., Ghaskadbi, S.S. and Lele, R.D. (2004). Free radicals and antioxidants in human health: current status and future prospects. The Journal of the Association of Physicians of India, 52, 794-804.

Dos Santos, W.N.L., da Silva Sauthier, M.C., dos Santos, A.M.P., de Andrade Santana, D., Azevedo, R.S.A. and da Cruz Caldas, J. (2017). Simultaneous determination of 13 phenolic bioactive compounds in guava (Psidium guajava L.) by HPLC-PAD with evaluation using PCA and Neural Network Analysis (NNA). Microchemical Journal, 133, 583-592. https://doi.org/10.1016/j.microc.2017.04.029

Freda, S.A., Krumreich, F.D., Hartwig, N. and Zambiazi, R.C. (2018). Bioactive compounds during processing and storage of sweet guava (conventional and light). International Food Research Journal, 25(3), 1181-1188.

Halliwell, B. (1996). Antioxidants in human health and disease. Annual Review of Nutrition, 16(1), 33-50. https://doi.org/10.1146/ annurev.nu.16.070196.000341

Ho, R., Violette, A., Cressend, D., Raharivelomanana, P., Carrupt, P.A. and Hostettmann, K. (2012). Antioxidant potential and radical-scavenging effects of flavonoids from the leaves of Psidium cattleianum grown in French Polynesia. Natural Product Research, 26(3), 274-277. https:// doi.org/10.1080/14786419.2011.585610

Hoffmann-Ribani, R., Huber, L.S. and RodriguezAmaya, D.B. (2009). Flavonols in fresh and processed Brazilian fruits. Journal of Food Composition and Analysis, 22(4), 263-268. https:// doi.org/10.1016/j.jfca.2008.12.004

Khanam, U.K.S., Oba, S., Yanase, E. and Murakami, Y. (2012). Phenolic acids, flavonoids and total antioxidant capacity of selected leafy vegetables. Journal of Functional Foods, 4(4), 979987. https://doi.org/10.1016/j.jff.2012.07.006

Kondo, S., Kittikorn, M. and Kanlayanarat, S. (2005). Preharvest antioxidant activities of tropical fruit and the effect of low temperature storage on antioxidants and jasmonates. Postharvest Biology and Technology, 36(3), 309-318. https://doi.org/10.1016/ j.postharvbio.2005.02.003

Kubola, J. and Siriamornpun, S. (2011). Phytochemicals and antioxidant activity of different fruit fractions (peel, pulp, aril and seed) of Thai gac (Momordica cochinchinensis Spreng). Food Chemistry, 127(3), 1138-1145.

j.foodchem.2011.01.115

Kumar, V., Chauhan, S., Nagarajan, K. and Singh, B.K. (2015). Lycopene Potentiates the Protective Effect of Aliskiren on Doxorubicin-Induced Cardiomyopathy in Rats. Journal of Pharmacy and Nutrition Sciences, 5(3), 199-207. https:// doi.org/10.6000/1927-5951.2015.05.03.5

Lampila, P., van Lieshout, M., Gremmen, B. and Lähteenmäki, L. (2009). Consumer attitudes towards enhanced flavonoid content in fruit. Food Research International, 42(1), 122-129. https:// doi.org/10.1016/j.foodres.2008.09.002

Miean, K.H. and Mohamed, S. (2001). Flavonoid (myricetin, quercetin, kaempferol, luteolin, and apigenin) content of edible tropical plants. Journal of Agricultural and Food Chemistry, 49(6), 3106-3112. https://doi.org/10.1021/jf000892m

Mitra, S.K., Maiti, S.C., Sen, S.K. and Bose, T.K. (1983). Physico-chemical characters of some guava varieties of West Bengal. South Indian Horticulture, 31, 62-65.

Morton, J.F. (1987). Fruits of warm Climates. Miami, Florida, USA: Creative Resource Systems, Inc. 
Musa, K.H., Abdullaha, A. and Subramaniamb, V. (2015). Flavonoid profile and antioxidant activity of pink guava. Science Asia, 41, 149-154.

Ordóñez-Santos, L.E. and Vázquez-Riascos, A. (2010). Effect of processing and storage time on the vitamin $\mathrm{C}$ and lycopene contents of nectar of pink guava (Psidium guajava L.). Archivos atinoamericanos de Nutricion, 60, 280.

Perera, C.O. and Yen, G.M. (2007). Functional properties of carotenoids in human health. International Journal of Food Properties, 10 (2), 201-230. doi.org/10.1080/10942910601045271

Priam, F., Marcelin, O., Marcus, R., Jô, L.F. and SmithRavin, E.J. (2017). Lycopene extraction from Psidium guajava L. and evaluation of its antioxidant properties using a modified DPPH test. IOSR Journal of Environmental Science, Toxicology and Food Technology, 11(4), 67-73. https:// doi.org/10.9790/2402-1104016773

Rabinowitch, H.D., Sklan, D. and Budowski, P. (1982). Photo-oxidative damage in the ripening tomato fruit: Protective role of superoxide dismutase. Physiologia Plantarum, 54(3), 369-374. https://doi.org/10.1111/ j.1399-3054.1982.tb00273.x

Rani, D.J. and Vijayanchali, S.S. (2017). Phytochemical, Antioxidant Activity and Lycopene Analysis of Red Guava Fruits. Journal of Research, Extension and Development, 6, 25-30. https://doi.org/10.2139/ ssrn.3345542

Rao, M.V.S.S.T. and Muralikrishna, G. (2002). Evaluation of the antioxidant properties of free and bound phenolic acids from native and malted finger millet (Ragi, Eleusine coracana Indaf-15). Journal of Agricultural and Food Chemistry, 50(4), 889-892.

Rao, A.V. and Ali, A. (2007). Biologically active phytochemicals in human health: Lycopene. International Journal of Food Properties, 10(2), 279-288. https:// doi.org/10.1080/10942910601052673

Robbins, R.J. (2003). Phenolic acids in foods: an overview of analytical methodology. Journal of Agricultural and Food Chemistry, 51(10), 28662887. https://doi.org/10.1021/jf026182t

Rodriguez-Amaya, D.B. (2015). Status of carotenoid analytical methods and in vitro assays for the assessment of food quality and health effects. Current Opinion in Food Science, 1, 56-63. https://doi.org/10.1016/j.cofs.2014.11.005

Sies, H. and Stahl, W. (1995). Vitamins E and C, betacarotene, and other carotenoids as antioxidants. The American Journal of Clinical Nutrition, 62(6),
1315S-1321S.

https://doi.org/10.1093/ ajcn/62.6.1315S

Singh, R.V., Joshi, M.C., Ram, H.B. and Bishi, N.S. (1984). Effect of waxcoating and prepackaging on the storage behaviour of guava cv. Allahabad Safeda. Indian Food Packer, 38, 80-85.

Siriamornpun, S., Weerapreeyakul, N. and Barusrux, S. (2015). Bioactive compounds and health implications are better for green jujube fruit than for ripe fruit. Journal of Functional Foods, 12, 246-255. https://doi.org/10.1016/j.jff.2014.11.016

Siriamornpun, S. and Kaewseejan, N. (2017). Quality, bioactive compounds and antioxidant capacity of selected climacteric fruits with relation to their maturity. Scientia Horticulturae, 221, 33-42. https:// doi.org/10.1016/j.scienta.2017.04.020

Szeto, Y.T., TomLinson, B. and Benzie, I.F. (2002). Total antioxidant and ascorbic acid content of fresh fruits and vegetables: implications for dietary planning and food preservation. British Journal of Nutrition, 87(1), 55-59. https://doi.org/10.1079/ BJN2001483

Thuaytong, W. and Anprung, P. (2011). Bioactive compounds and prebiotic activity in Thailand-grown red and white guava fruit (Psidium guajava L.). Food Science and Technology International, 17 (3), 205-212. https:// doi.org/10.1177/1082013210382066

Wilberg, V.C. and Rodriguez-Amaya, D.B. (1995). HPLC quantitation of major carotenoids of fresh and processed guava, mango and papaya. LWT-Food Science and Technology, 28(5), 474-480. https:// doi.org/10.1006/fstl.1995.0080 